\title{
A COMPARISON OF AMITRIPTYLINE WITH CHLORDIAZEPOXIDE IN ANXIETY
}

\author{
Major R. D. GEORGE, M.B., B.S., R.A.M.C. \\ 31 Field Ambulance R.A.M.C., B.A.O.R. \\ Major R. C. MENZIES, M.B., Ch.B., R.A.M.C. \\ British Military Hospital, Rinteln
}

\begin{abstract}
SUMMARY: Fifty-three patients with mild to moderate anxiety took part in a six-week double-blind trial with either amitriptyline $30 \mathrm{mg}$ daily, amitriptyline $75 \mathrm{mg}$ daily or chlordiazepoxide $30 \mathrm{mg}$ daily. No statistically significant difference in percentage improvement of symptoms was shown between the three groups.
\end{abstract}

\section{Introduction}

It is widely accepted that an increasingly high percentage of patients attending the General Practitioner's surgery, do so because of minor psychiatric disturbances. This indeed has been the experience of the authors, working in general practice in the Armed Forces, where although there tends to be a bias towards the younger age groups who consequently have a higher degree of health and fitness, nevertheless the stresses and strains of living both in a military environment as well as in the 1970's produce a large number of such disturbances. Wawman (1973) notes, particularly amongst the wives and dependants of military personnel, the stressful aspects of service life such as separation of husband and wife, separation from parents, isolation in an unfamiliar environment, and the nomadic existance. Other indications of this liability to mental illness are given by McGhie and McConvell (1953) and Wallis (1968). In a recent survey of the clinical work of the psychiatric services based at the British Military Hospital, Singapore, Glen (1972) has indicated that over one third of patients seen by that department were either suffering from reactive depression or anxiety states.

We observed a similar picture in our own practice. We noted that a large number of these patients were treated with either a minor tranquilliser or an anti-depressant, and it seemed there was usually a marked improvement in the patient's condition whichever drug was used. Reference to the medical literature showed many examples of drug trials comparing these two forms of therapy singly, or in combination, in depressive illness. However there was no record of this in the case of anxiety. We therefore embarked on a trial to compare chlordiazepoxide with amitriptyline, in order to determine from which group of drugs best to choose, when treating these common minor psychiatric disturbances, particularly in relation to service dependants. It was decided to compare chlordiazepoxide with amitriptyline because both were well known; commonly used drugs.

\section{Patients and methods}

The trial was designed as completely randomised, double-blind and non-crossover, using two dosages of amitriptyline (30 $\mathrm{mg}$ and $75 \mathrm{mg}$ daily) against one dosage of chlordiazepoxide ( $30 \mathrm{mg}$ daily), each preparation was made up in identical capsules.

The fifty-three patients chosen for study were of either sex, between the ages of fifteen and sixty-five, suffering from a mild to moderate degree of anxiety, for whom a 
mild tranquilliser would usually have been prescribed by their general practitioner. Patients were automatically excluded if they were pregnant, or if they had received any previous psychiatric treatment or medication, or if they were found to be suffering from either severe anxiety or severe depression.

Each patient was initially assessed by the physicians before entering the trial and every two weeks thereafter during the trial period of six weeks. Patients were randomly divided into three groups. One group received amitriptyline $30 \mathrm{mg}$ daily in three divided doses, the second group amitriptyline $75 \mathrm{mg}$ daily in three divided doses, and the third chlordiazepoxide $30 \mathrm{mg}$ daily in three divided doses. The assessments of the patients were made according to the Hamilton Rating Scale. Note was also made of adverse reactions during these assessments.

\section{Results}

Figure 1 shows the percentage improvement in total symptoms in each of the three

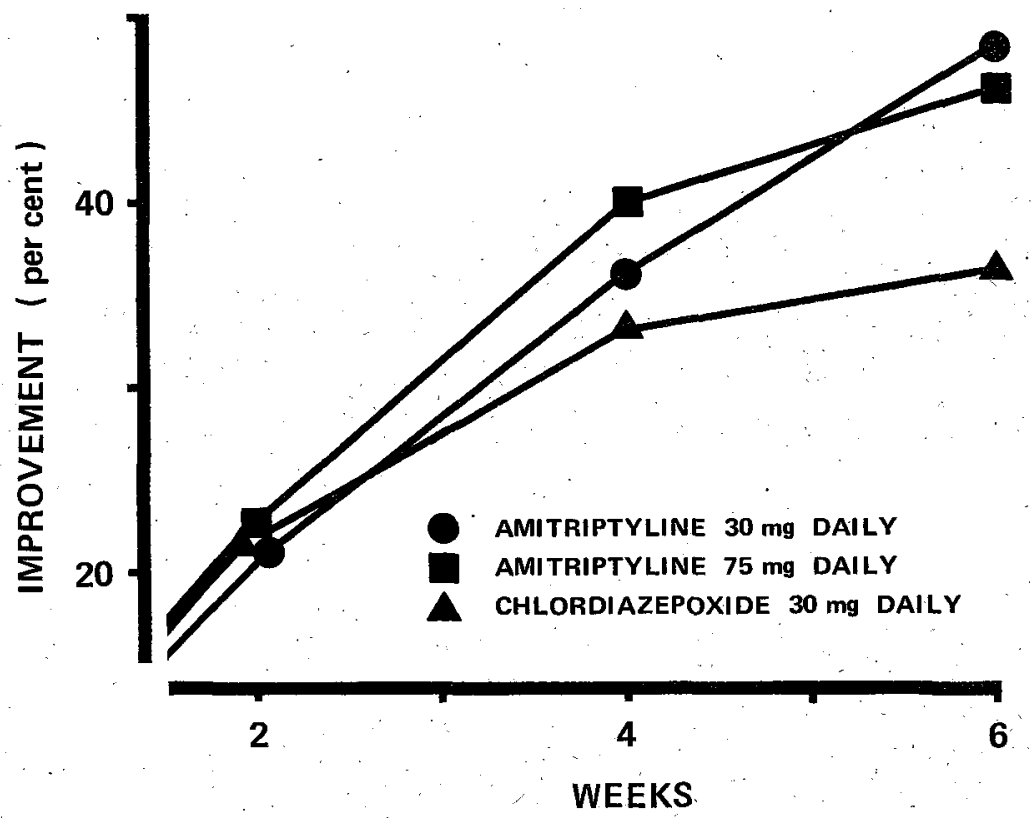

Fig. 1. Percentage improvement in total symptoms.

treatment groups during the six week period. At the end of the trial, percentage improvement in the amitriptyline $30 \mathrm{mg}$ daily group was 49 per cent; in the amitriptyline $75 \mathrm{mg}$ daily group it was 46 per cent and in the chlordiazepoxide $30 \mathrm{mg}$ daily group it was 37 per cent.

Figure 2 shows the percentage improvement in anxiety in each of the three groups during the trial. At the end of the six weeks the percentage improvement in the amitriptyline $30 \mathrm{mg}$ daily group was 58.5 per cent; in the amitriptyline $75 \mathrm{mg}$ daily group it was 58 per cent and in the chlordiazepoxide $30 \mathrm{mg}$ daily group it was 54 per cent.

Using the Mann-Waitney $U$ test there was no statistically significant difference between the three groups. Using the same test on the results at the week 2, 4 and 6 times; 


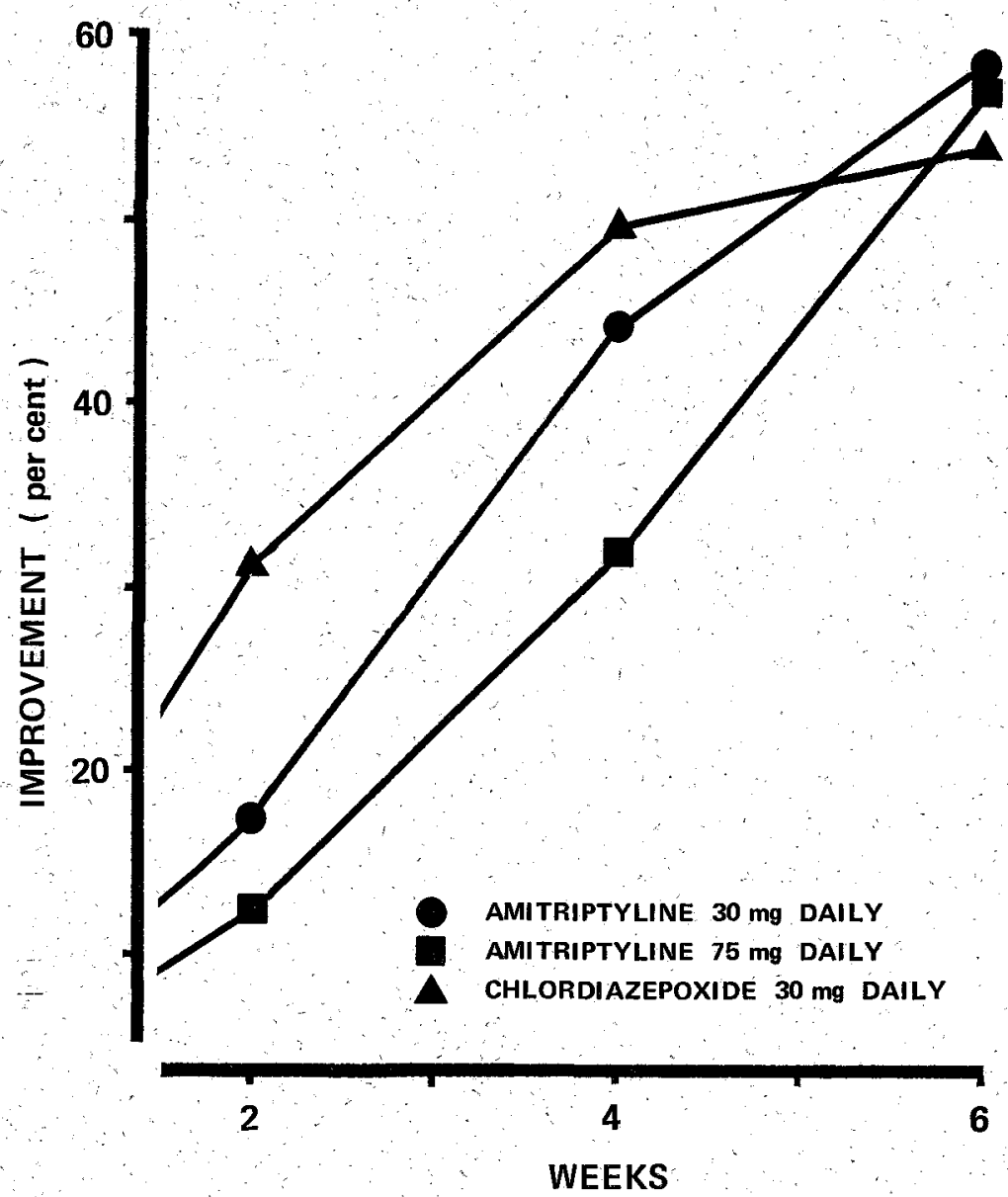

(Figs 1 and 2 produced by University of Manchester Department of Medical Illustration)

Fig. 2. Percentage improvement in anxiety.

there was still no statistically significant difference found between the three treatments.

Using the Kruskal Wallis one-way analysis of variance by ranks at 2,4 and 6 weeks the results again show no significant difference between the three treatment groups. the trial.

Due mainly to personal and domestic reasons, nineteen patients failed to complete

Drowsiness and dry mouth were the most common side effects in all three groups, and there was found to be no statistically significant difference between them.

\section{Discussion}

It appears from the results that all three treatments are equally effective against mild to moderate anxiety. Studying Figures 1 and 2 in more detail it is seen that both amitriptyline dosages produce a very similar improvement, irrespective of strength of dose. This is an indication that there is a low optimum therapeutic dosage for amitriptyline and higher doses do not produce proportionally higher effect. 
For most of the six week period the graphs for each of the three drug groups follow each other closely until almost the end of the trial. At this stage there is a suggestion that graphs of the amitriptyline are beginning to move away from that of chlordiazepoxide, indicating that if the trial had continued for longer than six weeks, the amitriptyline may have started to show a significantly better response than chlordiazepoxide.

In the case of graphs showing improvement with anxiety alone there is an initial delay of two to four weeks before the response of the amitriptyline graphs challenge and eventually overtake the chlordiazepoxide.

Both of these points indicate that amitriptyline is slower to act than chlordiazepoxide, which is in agreement with current teaching on the speed of action of amitriptyline in the case of depression. If the trial had been continued longer, then amiptriptyline might have produced a significantly higher percentage improvement, which is also in keeping with the findings of other authors.

In many ways the results of the trial could have been anticipated, since the relationship between anxiety and depression is complex. They often occur together and are often difficult to distinguish one from the other. This may be explained by the fact that the hypothalmus and limbic system control both of these emotional states as noted by Kelly (1973). It is therefore evident that drugs which influence depression might be expected to modify anxiety.

In view of the similarity between the therapeutic effect of amitriptyline and chlordiazepoxide under these conditions, at least over the limited time period of the trial, the choice of drug to be used in future may well have to depend on the evaluation of their side effects.

In conclusion, from the results of the trial it would appear that all three treatments are equally effective against mild to moderate anxiety. It is also reasonable to suggest that because of the close clinical relationship between anxiety and depression it would be correct to use amitriptyline rather than chlordiazepoxide, thus avoiding the possibility of overlooking an underlying depression, with its potentially serious consequences.

\section{REFERENCES}

Glen, D. W. F. (1972). J. roy. Army med. Cps. 118, 135.

KELLY, D. (1973). Practitioner 210, 44.

MCGHIE, J. and MCConvell, D. J. (1953). J. roy. Army med. Cps 99, 228.

Wallis, C. F. (1968). Proc. roy Soc Med 61, 976

WaWMan, R. J.(1973) J roy. Army med. Cps 119, 14.

Other relevant literature

Anderson, J., Lambert, N. G. and Pigott, P. V. (1972). Practitioner 208, 511.

ANON (1969). Practitioner 202, 437:

AYD, F. J. (1965). Dis. nerv. Syst 26, 719.

Drugs and Therapeutic Bulletin (1969). Vol: 7. No. 19.

Hamil toN, M. (1960). J. Neurol. Neurosurg. Psychiat. 23, 56. 